\title{
Big data and evaluation of cultural ecosystem services: an analysis based on geotagged photographs from social media in Tuscan forest (Italy)
}

\begin{abstract}
lacopo Bernetti, Gherardo Chirici, Sandro Sacchelli
\end{abstract}

\begin{abstract}
The paper presents a methodology to quantify the suitability of forest stands for the potential delivery of cultural ecosystem services (CES). The quantification of CES represents a complicated task in the framework of ecosystem service valuation. Compared to traditional investigations, focusing on the study of the aesthetic appreciation of a particular territory, the use of geotagged photographs seems to be a promising alternative to appraise CES. Thus, in order to analyse CES with a particular focus on the aesthetic appreciation of forest stands, this study exploits big data through the analysis of photos shared on the Flickr social network. Crowdsourced datasets are used to depict the geographic location and density of pictures - expressed as the number of photos per unit of surface - as well as their relationship to forest variables and logistic characteristics. The implemented geostatistical model is used to spatialise the results at the regional level (Tuscany forests, Italy). Among the outputs, high values of CES are stressed for high forest and protected areas. From a forest species viewpoint, silver fir, coastal Mediterranean pine, beech and mixed forests seem to be more appreciated compared to other stand typologies such as oaks (e.g., pubescent or Turkey oak) and thermophilic broad-leaved species. Additional quantitative parameters (e.g., elevation, biomass stock and distance to main roads) were significant to the CES assessment. The potential applications of the technique to support forest planning and management are discussed.
\end{abstract}

Keywords: Forest Aesthetic Value, Social Network, Maximum Entropy Models, Tag-cloud, Geographic Information Systems
2016 and is forecast to rise by $4.0 \%$ in the 2017-2027 period. Growth will mostly come from nature-based tourism (Balmford et al. 2009); thus, the potential economic value is high and may have considerable potential to generate funds for conservation and people engaging with the environment. The World Tourism Organization estimates that ecotourism represents $2-4 \%$ of the entire world tourism market and has an annual growth potential of approximately $20 \%$.

Monetisation can be a path for planning rural-related projects and the quantification of CES (Nesbitt et al. 2017). However, among other categories of ecosystem serthe global gross domestic product (CDP) in strong economic importance (HernándezMorcillo et al. 2013, Milcu et al. 2013). Travel and tourism directly accounted for $3.1 \%$ of

\footnotetext{
$\square$ Department of Agricultural, Food, Environment and Forestry, University of Florence, p.le delle Cascine 18, v. S. Bonaventura 13, Firenze (Italy)
}

@ Sandro Sacchelli (sandro.sacchelli@unifi.it)

Received: Apr 19, 2018 - Accepted: Nov 22, 2018

Citation: Bernetti I, Chirici G, Sacchelli S (2019). Big data and evaluation of cultural ecosystem services: an analysis based on geotagged photographs from social media in Tuscan forest (Italy). iForest 12: 98-105. - doi: 10.3832/ifor2821-011 [online 2019-02-11] vices (ES), i.e., provisioning, supporting and regulating services, the quantification of the economic value of CES is a tricky issue. This is mainly due to its scarce tangibility and to the influence of subjective issues in valuation (Rabe et al. 2018). Moreover, the difficulty of spatialising monetary values with proper detail (resolution) is highlighted in the literature (Carvalho-Ribeiro et al. 2016). To cope with these challenges, a series of alternative methods, compared to those used in economic analysis, have been applied to quantify CES (Fontana et al. 2013, Nahuelhual et al. 2013, Brown \& Fagerholm 2015, Saarikoski et al. 2016, Rovai et al. 2016, Pastorella et al. 2017, Dunford et al. 2018). Allowing for the subjective evaluation of participative processes, the above research represents a milestone for CES analysis.

Some advances have been recently introduced by the application of big data, and specifically by social media analysis (Langemeyer et al. 2018, Oteros-Rozas et al. 2018). Focusing on the study of the aesthetic appreciation of a particular rural area or landscape, compared to traditional investigation, the use of geotagged photographs seems to be a promising alternative to appraising CES. In the last decades, the evaluation of ES through web-based pho- 


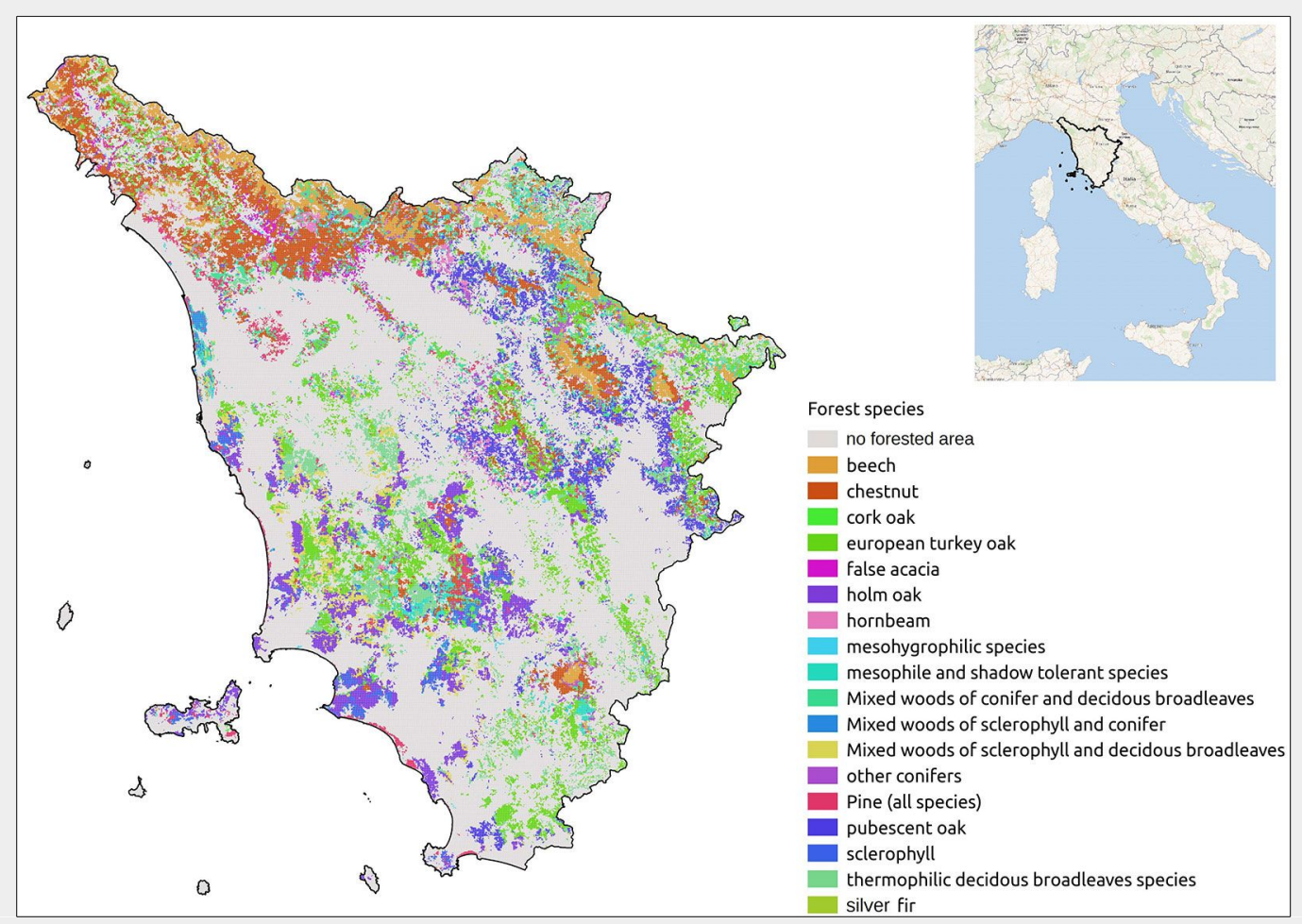

Fig. 1 - Forest species distribution in Tuscany (central Italy).

tographs has developed as a method for the analysis of rural landscapes and natural areas. The volume and spatial distribution of geotagged photographs uploaded to global online social media platforms (Instagram $^{\mathrm{TM}}$, Panoramio ${ }^{\mathrm{TM}}$ or Flickr ${ }^{\mathrm{TM}}$ ), can be a useful source of data for mapping the distribution of CES (Cao \& O'Halloran 2015 Hollenstein \& Purves 2010, Li et al. 2013, Sun et al. 2013). The main advantages of us ing geotagged photographs as a proxy for people's preferences are (i) using the observed preferences (Hollenstein \& Purves 2010) and (ii) obtaining precise information on the actual provision of the service provided by the exact position in which the photos are taken (Bagstad et al. 2014). Levin et al. (2017) found "strong and significant correlations between all crowdsourced data and visitation statistics, demonstrating the potential of using crowd sourced data to characterize the social and perceived importance of protected areas as a proxy for visitation statistics".

Yoshimura \& Hiura (2017) and WaldenSchreiner et al. (2018) have analysed the relationships between the shooting locations of georeferenced photos on Flickr ${ }^{\mathrm{TM}}$ with both the environmental characteristics of the territory and the presence of infrastructure. The aim of the authors was to deliver management strategies for the conservation of natural resources, while providing opportunities for tourism and recre ation.

From a land use point of view, several studies have focused on mountainous areas to depict both landscape characteris tics relevant for aesthetic appreciation (Tenerelli et al. 2016) and the drivers used to map outdoor recreation supply, demand, and flow (Schirpke et al. 2018). Urban green spaces have been investigated with a focus on general (e.g., managed and spontaneous vegetation, including public parks, gardens as well as nature reserves Richards \& Tunçer 2017) or specific land use typologies (mangrove urban forest - Richards \& Friess 2015).

According to the authors' knowledge, there is a lack of specific studies dealing with the assessment of CES in forest stands using big data from social media, with a specific focus on aesthetic appreciation. In this context, a methodological approach to quantifying the aesthetic value of the forest environment and its spatial associations with the features of forest stands on a regional scale, is proposed. Specifically, the objectives of the work are: (i) to create a spatial model to evaluate the provision of aesthetic value in forests; and (ii) to identify which biophysical and infrastructural variables better explain the spatial distribution of this CES. The results can represent a preliminary step to guide policy-and decision-makers in planning as well as the management of forests to optimize the delivery of CES.

\section{Methods}

\section{Study area}

The CES provision has been set at regional level (Tuscany region, central Italy) because operational actions regarding the Common Agricultural Policy in Italy are delegated to the regions (NUTS-2 subdivision, according to Eurostat classification). This administrative level could favour the depiction and addressing of the EU funds available for particular agroforestry interventions. The forested area of Tuscany is $1,086,000$ hectares, equal to $47 \%$ of the re- gional territory. The stand area is mainly composed by deciduous oak (primarily Turkey oak and downy oak with 414,000 ha), followed by forests with a prevalence of chestnut (177,000 hectares). The mountainous territory is characterized by beech (76,000 ha), firs (14,000 ha) and black pine (21,000 ha). In the coastal areas, there are widespread holm oak, Mediterranean scrub and Mediterranean pines (e.g., Italian umbrella pine and Maritime pine). From a silvicultural point of view, compared to the high forest (34\%), there is a clear prevalence of coppice (66\%), which is more concentrated in the mountainous forests, especially in the beech and oak stands (our elaboration on Tuscany region data - http:// www.regione.toscana.it/-/geoscopio). Fig. 1 shows the distribution of forest species in the study region.

\section{Geotagged photo acquisition}

Recently, there has been a rapid increase in the available data sources regarding voluntary geographical information. Social media applications such as Twitter $^{\mathrm{TM}}$, Flickr $^{\mathrm{TM}}$ and Facebook ${ }^{\mathrm{TM}}$ provide a collection of geographical information that can be queried via public application programming interfaces (APIs). In addition, a growing willingness of people to actively contribute in sharing their experiences of living in urban, rural and natural spaces is being witnessed. This phenomenon is known by the generic term "people as sensors" (Kirilenko et al. 2015).

In this study, the most used platform to share photographic images, Flickr ${ }^{\mathrm{TM}}$, is used. Flickr ${ }^{\mathrm{TM}}$ has been involved in several scientific research studies focused on data sources in GIScience, geography, and tourism. The platform offers an accessible 
API and has experienced continuous growth (Alivand \& Hochmair 2017). Previous studies (Levin et al. 2017) have shown how Flickr ${ }^{T M}$ provides a source of information that is free, updated, and with good spatial as well as temporal resolution. The potential analysis of the tags' contents is a further strength of the platform.

According to Nov et al. (2010), the photographic data uploaded on Flickr ${ }^{\mathrm{TM}}$ imply an individual process that can be divided into two main phases: (i) the technical-creative phase of taking the photo; (ii) the social phase of sharing this photo integrated with an association of comment/s on it.

The action of taking a picture is not only linked to the characteristics of the surrounding environment; it also involves other aspects of interpretative cognition that people apply to that space (personal preferences, memories, opinions, etc. Dakin 2003, Scott \& Canter 1997). Both the act of taking a picture in a specific place and the action of choosing which photo to share reflect the quality perceived by the individual about that place.

Geotagged photos were queried from the Flickr $^{T M}$ API using the statistical software $R$ (version 3.2.5). The downloaded attributes of geotagged photo include latitude, longitude, owner, acquisition date, text tag, accuracy evaluation, and image URL. Pictures taken during the period from 01/01/2010 to $31 / 12 / 2017$ were downloaded for a total of over 1.6 million photos in Tuscany (Where On Earth Identifier - WOEID = 7153345), mainly in the city of Florence. A dataset containing the georeferenced photo points loaded during this period was created by means of an overlay with a forest map. The dataset contains 65,418 georeferenced photos. The positional accuracy was set at street level (provided level of positional accuracy from Flickr ${ }^{\mathrm{TM}} \geq 12$ - Flickr 2018). The records were analysed in $\mathrm{R}$ and converted into a shapefile for geospatial analysis using the QGIS software. The pictures containing tags relevant to forest depiction (e.g., wood, forest, tree and other synonyms and related words) were filtered using a QGIS query whose extended expression is provided in the Supplemental material. This step is needed to select the photos inside the forest that focus on wood-related elements. Eventually, specific filters were applied to avoid distortions due to photos being repeated many times in a single location by a single photographer. The final dataset contained 7,986 photographic points. To verify the correctness of the final database, a frequency analysis of the words contained in the tags was carried out.

\section{Variable data sources}

Explanatory variables are used to understand which characteristics of the forest influence an individual's decision to take a picture and publish it on Flickr ${ }^{\mathrm{TM}}$. The variables used are the distance from main roads to forest paths, the distance to the coast line, the geomorphological characteristics (altitude and slope), the forestry parameters (forest species and regeneration, i.e., management system, fertility class and biomass stock), and the level of environmental protection (national parks, regional parks, reserves and other protected areas). The distance to the main roads was chosen because roads are the main access infrastructure to the forest. Furthermore, this factor is a component of management plans and represents the ways in which agencies provide services to visitors and mitigate impacts. The coast in Tuscany denotes the non-urban localization of greater tourist pressure. The forests close to it (mainly with a prevalence of Italian umbrella pine) are particularly vulnerable to tourist overload. In the study area, the altitude and the slope are strongly correlated to the climate (rainfall and temperature) and influence the use of the forest. The forestry variables were chosen based on the literature on recreation in forests (Diktas 2017, Komossa et al. 2018). None of these variables had a significant correlation to each other (all $r<0.4$ ), thus excluding the risk of multicollinearity. All the independent variables were original or were resampled at a resolution of 1 ha (cell size 100 $\mathrm{m}$ ). The list of variables and their sources are shown in Tab. 1.

\section{Statistical model}

The purpose of the statistical analysis was to create a map of the probability that an individual takes a photo of a forest and shares it on the Flickr ${ }^{\mathrm{TM}}$ platform. This map can be considered as a proxy for the value of CES (Schirpke et al. 2016). Maximum entropy models (MaxEnt) have been applied with success in managing visitor impacts on natural resources including human-nature interactions (Braunisch et al. 2011) and off-road recreational behaviour prediction (Coppes \& Braunisch 2013, Westcott \& Andrew 2015). MaxEnt has only recently been applied to the estimation of CES through correlations between the locations of Flickr photos with the environmental characteristics of the territory (Yoshimura \& Hiura 2017, Walden-Schreiner et al. 2018). The

Tab. 1 - Description of the geographical dataset used in the analysis.

\begin{tabular}{l}
\hline Dataset \\
\hline Forest species map. Categories: (1) holm oak; (2) cork oak; (3) pubescent oak; (4) \\
european turkey oak; (5) hornbeam; (6) chestnut; (7) false acacia; (8) beech; (9) silver \\
fir; (10) sclerophyll; (11) thermophilic decidous broadleaves species; (12) mesohygro- \\
philic species; (13) mesophile and shadow tolerant species; (14) Pine (all species); (15) \\
other conifers; (16) Mixed woods of sclerophyll and conifer; (17) Mixed woods of sclero- \\
phyll and decidous broadleaves; (18) Mixed woods of conifer and decidous broadleaves. \\
Regeneration system map. Categories: (1) high forest; (2) coppice.
\end{tabular}

Protected areas map. Categories: (1) national parks; (2) regional parks; (3) nature reserves; (4) local parks; (5) unprotected forests.

Digital Terrain Model (DTM)

$$
\begin{aligned}
& \hline \text { Slope } \\
& \text { Road map } \\
& \text { Map of distance from road } \\
& \text { Coastline map } \\
& \hline
\end{aligned}
$$

Map of distance from coastline

Soil fertility map. Categories: Ordinal classes progressively increasing from 1 (high fertility) to 7 (low fertility).

Biomass stock map

\section{Source}

Tuscany Region -

http://www.regione.toscana.it/-/geoscopio

Tuscany Region -

http://www.regione.toscana.it/-/geoscopio

Tuscany Region -

http://www.regione.toscana.it/-/geoscopio

Tuscany Region -

http://www.regione.toscana.it/-/geoscopio DTM processing using QGIS software

Tuscany Region -

http://www.regione.toscana.it/-/geoscopio

Elaboration of the road map via QGIS software

National Geoportal, Ministry of Environment http://www.pcn.minambiente.it/mattm/

Elaboration of the coastline map via QGIS software

Tuscany Region -

http://www.regione.toscana.it/-/geoscopio

Geolab laboratory, University of Florence 
Fig. 2 - Tag-cloud of filtered photo points.

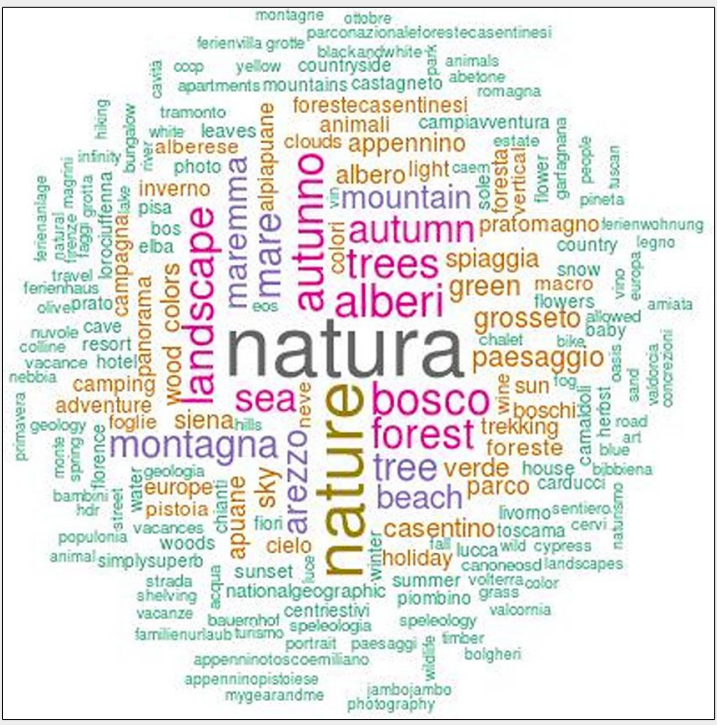

Fig. 3 - Probability map of visitor presence.

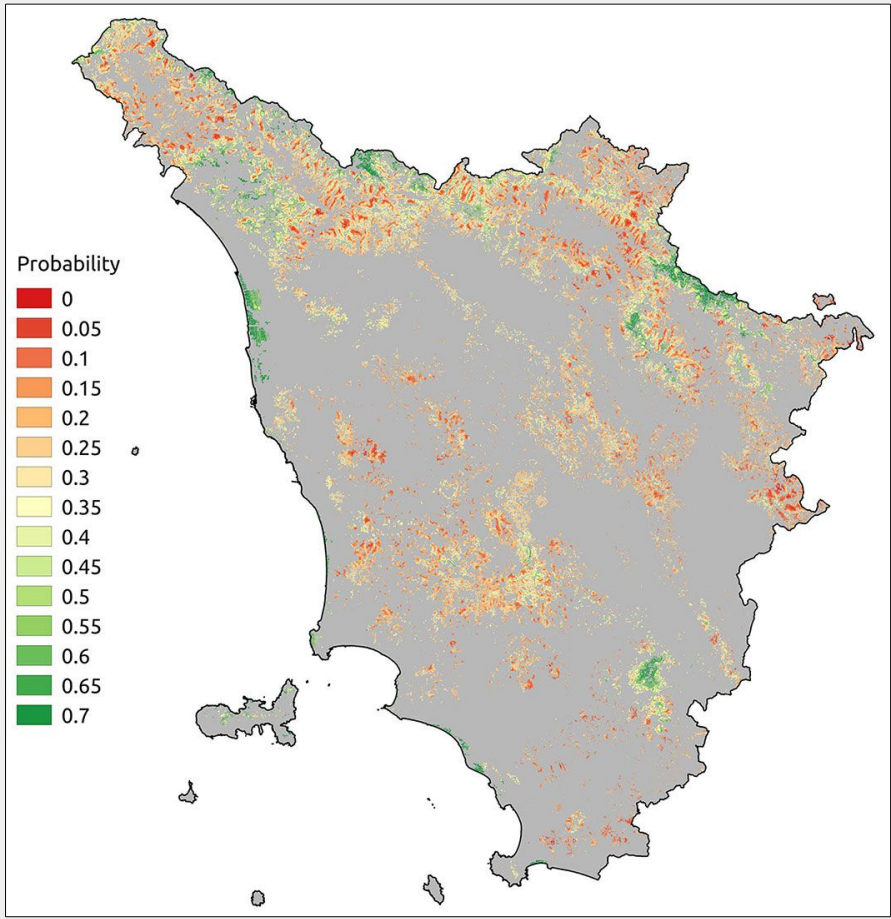

Fig. 4 - Receiver operating characteristic (ROC) curve.

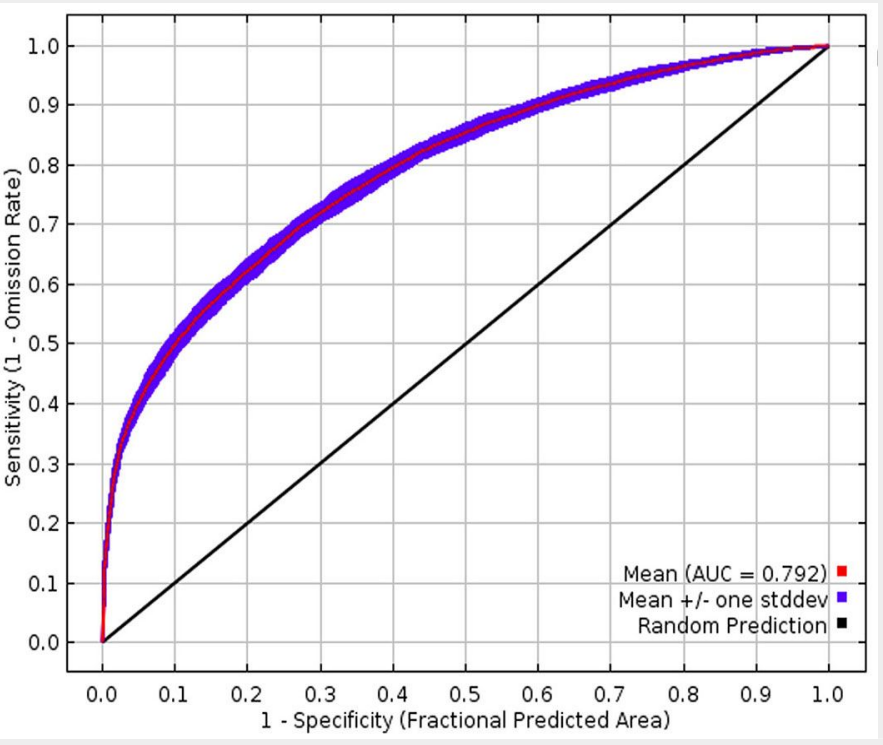

MaxEnt models integrate continuous and categorical predictive variables, minimize over-treatment and evaluate the influence of each covariate.

The applied model was based on 30 replicas. The maximum number of background points has been set to 10,000 with a convergence threshold of 0.00001 (Phillips et al. 2006, Poor et al. 2012, Merow et al. 2013). The area under the curve (AUC) of the receiver operating characteristic (ROC) chart was used as a first parameter to validate the MaxEnt model (Phillips \& Dudík 2008). ROC can measure the efficiency of a binary classifier such as the MaxEnt model, and the AUC represents the probability of sensitivity. An AUC value of 0.5 indicates a random pattern, while a value of 1 indicates a model that perfectly classifies the data presence. An AUC value of 0.50-0.70 suggests a fairly accurate model, a value of $0.70-0.90$ suggests an accurate model, and a value greater than 0.90 indicates an extremely accurate model (Swets 1988). A useful result of the MaxEnt model is the response curve. The curve shows how the probability of prediction varies with each environmental variable, keeping all the other variables at the average value of the sample. Subsequently, a jackknife analysis was used to indicate the most informative variables. The jackknife test obtained from MaxEnt allows an analysis of the contribution of each environmental variable to taking and sharing pictures. When running the model, this approach excludes all variables apart one at a time.

\section{Results}

The tag-cloud shown in Fig. 2 demonstrates the relationship between the photos shared on Flickr ${ }^{\mathrm{TM}}$ and the primarily perceived forest element/s. Indeed, the word clouds not only show what people have seen but also what has been perceived as significant from an experiential/emotional viewpoint. The main aspects that emerge from the word cloud are related to the identification of the subject of the photos (e.g., the terms "nature/natura"), as well as the combination of places (Foreste Casentinesi, Alpi Apuane, Maremma, etc.) with other components. In particular, the words that seem to be relevant are related to recreational experiences (hiking, beach, camping, adventure, etc.), the characteristics of the forest ecosystem (mountain, chestnut, leaves, flowers, colours, etc.), the seasons of the year, and additional generic terms and perceived aspects (sea, light, green, etc.). The correct localization of the Flickr ${ }^{T M}$ points is confirmed by the combination of some tags related to the protection level (Foreste Casentinesi is a national park and Alpi Apuane and Maremma are regional parks), with words identifying the perception of forest and tree species (forest, cypress, pine, chestnutwood, etc.)

The probability map of visitor presence (Fig. 3) shows high probabilities along the 
Fig. 5 - Marginal response curves for the qualitative variables.

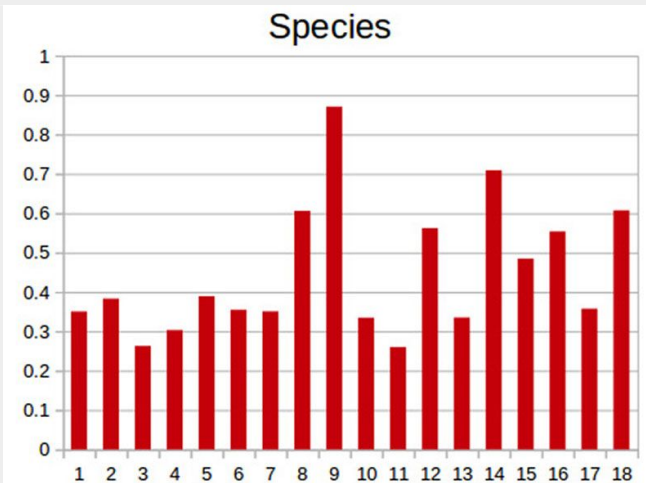

Parks

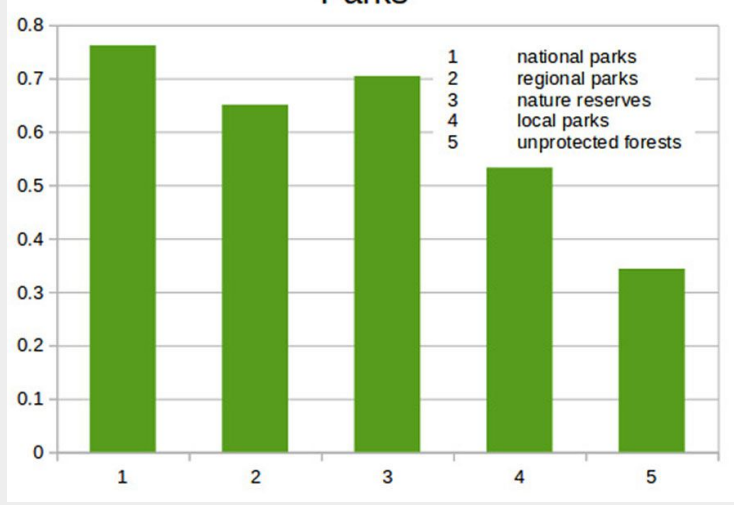

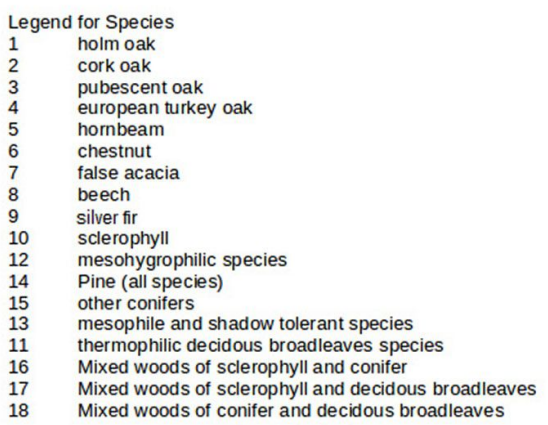

Regeneration system

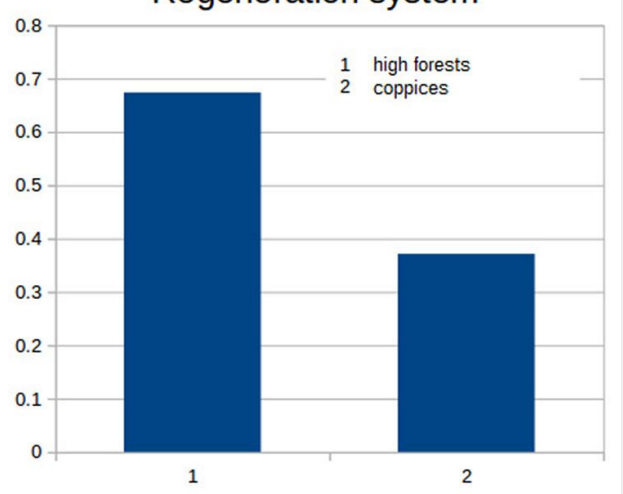

coastal areas, in the mountains of the Apennines and in the south-eastern area of the region (Monte Amiata). The MaxEnt model predicts an AUC of 0.792 (Fig. 4), stressing a good discrimination. The response curves (Fig. 5) show that visitors prefer forests with a prevalence of silver fir, pine, beech or mixed forests of conifers and broadleaved trees. The species that are less preferred by the visitors are the forest of pubescent and Turkey oak as well as the thermophilic broad-leaved woods. The contribution to the probability is rather differentiated, with a maximum of 0.87 for the silver fir and a minimum of 0.26 for the thermophilic forest. From a management perspective, the high forests are strongly preferred to coppices (the contribution to the probability is 0.67 and 0.31 , respectively). The level of protection is significant for CES quantification: the presence of natural protected areas highlights a relevant difference (contribution to the probability is 0.76 ) compared to forests without protection (contribution to the probability is 0.34 ). The response curves of the quantitative variables (Fig. 6) indicate how the distance from the roads to forest paths has a decreasing trend, with a very low probability of visitor presence for distances over 500 metres. Instead, the altitude and the distance to the coast are bimodal, with a high probability at sea level and in moun-
Fig. 6 - Marginal response curves for the quantitative variables. (a) Elevation (DTM, in m a.s.l.); (b) distance to coast (DistCost, $\mathrm{m})$; (c) distance to roads (DistRoad, $\mathrm{m}$ ); (d) biomass stock (Biomass, $\mathrm{m}^{3}$ ).

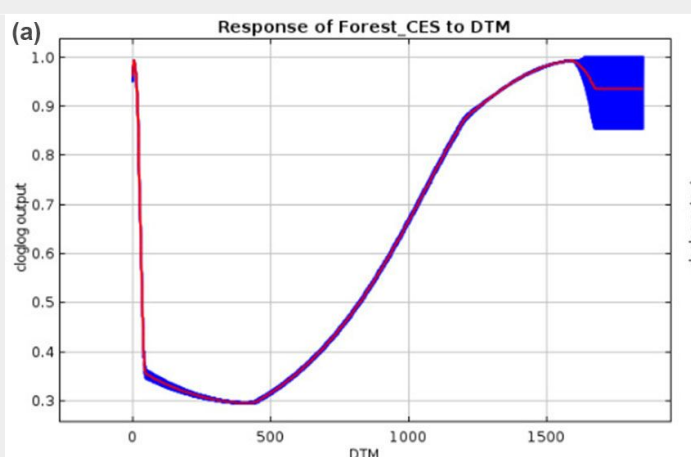

(c)

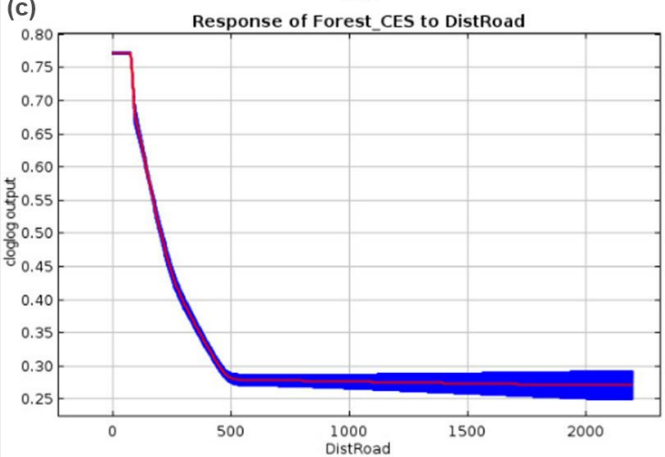

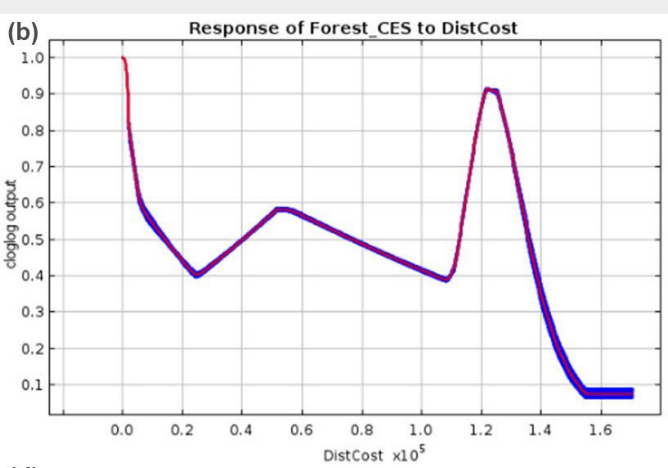

(d)

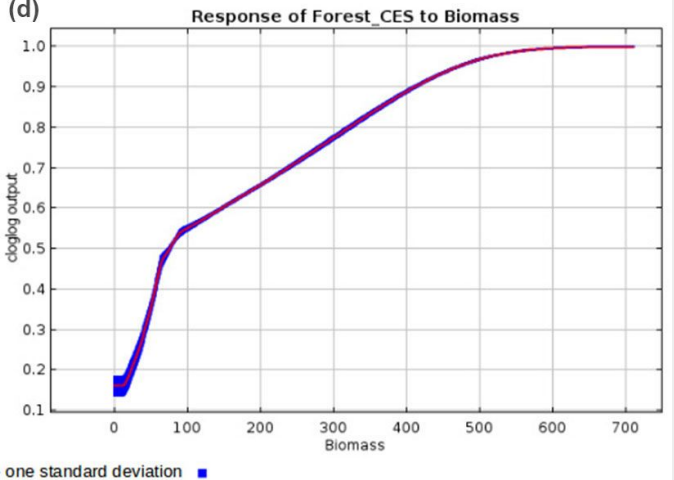




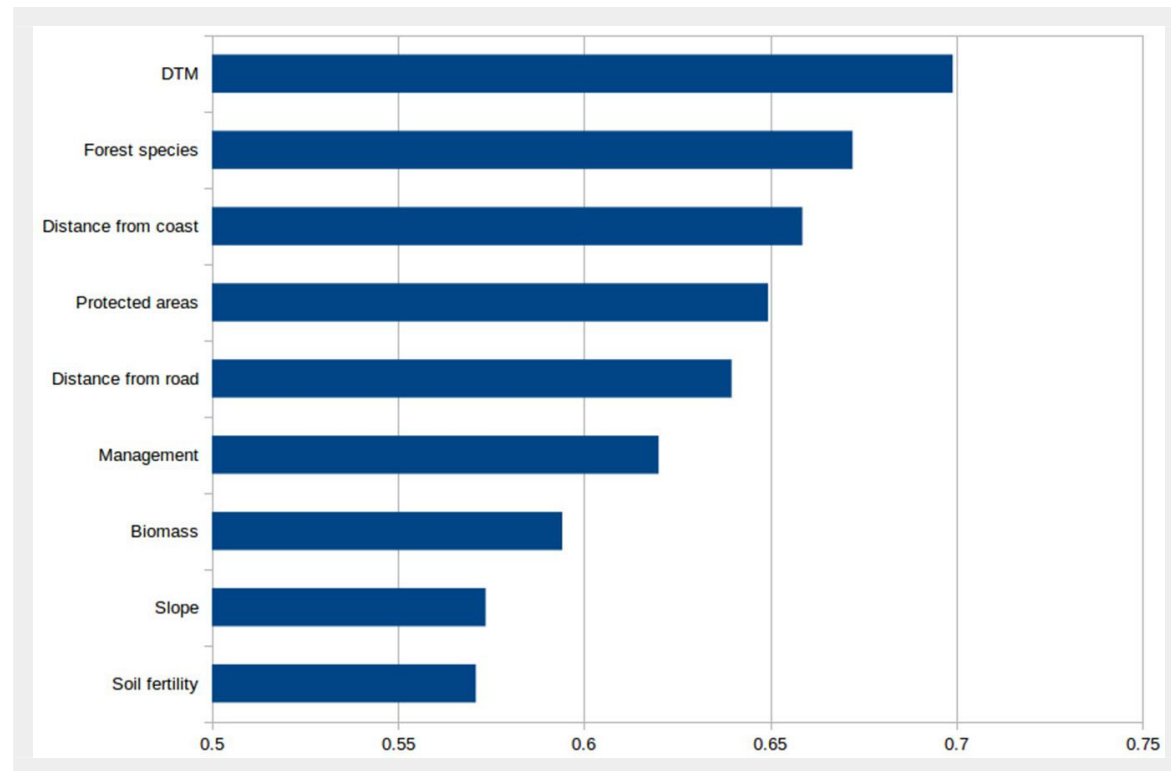

Fig. 7 - Results of the jackknife test (x-axis: AUC). chelli 2018). The outputs report a low significance of slope and fertility variables.

As confirmed by the AUC values, the results are significant from a statistical viewpoint.

The above considerations could be of great importance to depict the guidelines for forest planning and management. If the valorisation of CES is a priority, the maintenance of even-aged high forests or a conversion from coppice to high forest management should be a valid option for analysis. In the case of creating photography hunting paths, particular attention could be paid to the establishment of openness in the proximity of main roads as well as forest tracks. In general, at regional level, silvicultural practices take place only if there is an economic advantage (positive stumpage value from final harvesting or thinning - Fratini 2005). These typologies of intervention are mainly focused on provisioning services and the extraction of timber and firewood. Specific silvicultural treatments for the valorisation of CES focused on aesthetic improvement are not frequent in the study area. The negative stumpage values limit the interventions in public forests to the maintenance of safety standards for visitors. Scientific evidence for the relationship between forest management and the improvement of CES could promote suitable silvicultural practices for aesthetic enhancement. For example, Tahvanainen et al. (2001) revealed how small clear cutting had a positive effect on scenic beauty, depending on different variables such as the size of the gap, its adaptability to the landscape and the amount of logging residues left in the cutting area. Additional, future evaluations related to forest management should focus on the differences between photos concerning internal forest characteristics and scenic (landscape) beauty, e.g., through an automatic classification of image content. In fact, different authors have highlighted that thinning reduces the scenic value of the landscape, but it seems to have had no significant effect on the recreational value (Brunson \& Shelby 1992, Tahvanainen et al. 2001, Lupp et al. 2013). On the other hand, a natural state of the forest can be appreciated for recreational use but had no effect on scenic beauty (Tahvanainen et al. 2001). Territorial marketing activities can be promoted by means of the application of big data to create a web-based localization of high quality CES delivery areas.

A criticism of this method could be that often social media are used more to complain than to appreciate things in a positive way. However, thanks to the words associated with the pictures and provided on Flickr's post (Fig. 2), the photos could be classified as representing positive appreciation.

\section{Conclusion}

We believe that the method we applied can promote an advancement in CES local- 
ization and quantification compared to available literature focusing on forest systems. The indicators and variables derived from social media represent useful information for rapid and cost-effective assessments of CES. Thanks to the availability of API queries, the suggested technique and database can be easily updated and transferred to other case studies. The methodology facilitates application from small- to large-scale analyses.

Future analyses can attempt to apply methods for automating the content analysis of social media photographs. In this sense, the online machine learning algorithm based on Google Cloud Vision ${ }^{\text {TM }}$ could be tested to classify the content of images in forested areas (Richards \& Tunçer 2017). Further improvement should consider the seasonality of aesthetic appreciation and the time-dependence of geotagged photographs. The application of the proposed methodology to support forest management and planning for CES promotion should however consider spatial and temporal (intra-rotation period) variability, as well as trade-off and potential impacts among different ecosystem services at local or regional level.

\section{References}

Alivand M, Hochmair HH (2017). Spatiotemporal analysis of photo contribution patterns to Panoramio and Flickr. Cartography and Geographic Information Science 44 (2): 170-184. doi: 10.1080/15230406.2016.1211489

Bagstad KJ, Villa F, Batker D, Harrison-Cox J, Voigt B, Johnson GW (2014). From theoretical to actual ecosystem services: mapping beneficiaries and spatial flows in ecosystem service assessments. Ecology and Society 19 (2): 64 . doi: 10.5751/ES-06523-190264

Balmford A, Beresford J, Green J, Naidoo R, Walpole M, Manica A (2009). A global perspective on trends in nature-based tourism. PLoS Biology 7 (6): e1000144. - doi: 10.1371/journal.p bio.1000144

Braunisch V, Patthey P, Arlettaz R (2011). Spatially explicit modeling of conflict zones between wildlife and snow sports: prioritizing areas for winter refuges. Ecological Applications 21 (3): 955-967. - doi: 10.1890/09-2167.1

Brown G, Fagerholm N (2015). Empirical PPGIS/ PGIS mapping of ecosystem services: a review and evaluation. Ecosystem Services 13: 119-133. doi: 10.1016/j.ecoser.2014.10.007

Brunson M, Shelby B (1992). Assessing recreational and scenic quality. How does New Forestry rate? Journal of Forestry 90: 37-41. [online] URL: http://academic.oup.com/jof/articleabstract/90/7/37/4635574

Cao Y, O'Halloran K (2015). Learning human photo shooting patterns from large-scale community photo collections. Multimedia Tools and Applications 74 (24): 11499-11516. - doi: 10.1007/ s11042-014-2247-0

Carvalho-Ribeiro S, Correia TP, Paracchini ML, Schüpbach B, Sang AO, Vanderheyden V, Southern A, Jones P, Contreras B, Riordan T (2016). Assessing the ability of rural agrarian areas to provide cultural ecosystem services (CES): a multi scale social indicator framework (MSIF). Land Use Policy 53: 8-19. - doi: 10.1016/j.landuse pol.2015.04.024

Coppes J, Braunisch V (2013). Managing visitors in nature areas: where do they leave the trails? A spatial model. Wildlife Biology 19 (1): 1-11. doi: $10.2981 / 12-054$

Dakin S (2003). There's more to landscape than meets the eye: towards inclusive landscape assessment in resource and environmental management. The Canadian Geographer/Le Géographe Canadien 47 (2): 185-200. - doi: 10.1111/15 41-0064.t01-1-00003

Diktas BN (2017). An approach to determining forest areas with recreational potential: the case of forest areas around main transportation roads in the Maçka Region of Trabzon, Turkey. Journal of Sustainable Forestry 37(3): 286301. - doi: 10.1080/10549811.2017.1406374

Dunford R, Harrison P, Smith A, Dick J, Barton DN, Martin-Lopez B, Kelemen E, Jacobs S, Saarikoski H, Turkelboom F, Verheyden W, Hauck J, Antunes P, Aszalós R, Badea O, Baró F, Berry P, Carvalho L, Conte G, Czúcz B, Garcia Blanco G, Howard D, Giuca R, Gomez-Baggethun E, Grizetti B, Izakovicova Z, Kopperoinen L, Langemeyer J, Luque S, Lapola DM, Martinez-Pastur G, Mukhopadhyay R, Roy SB, Niemelä J, Norton L, Ochieng J, Odee D, Palomo I, Pinho P, Priess J, Rusch G, Saarela SR, Santos R, Van Der Wal JT, Vadineanu A, Vári A, Woods $\mathrm{H}$, Yli-Pelkonen $\checkmark$ (2018). Integrating methods for ecosystem service assessment: experiences from real world situations. Ecosystem Services 29: 499514. - doi: 10.1016/j.ecoser.2017.10.014

Eggers J, Lindhagen A, Lind T, Lämås T, Ohman K (2018). Balancing landscape-level forest management between recreation and wood production. Urban Forestry and Urban Greening 33: 1-11. - doi: 10.1016/j.ufug.2018.04.016

Flickr (2018). Flickr API documentation. Web site. [online] URL: http://www.flickr.com/services/ api/flickr.photos.search.html

Fontana V, Radtke A, Bossi Fedrigotti V, Tappeiner U, Tasser E, Zerbe S, Buchholz T (2013). Comparing land-use alternatives: using the ecosystem services concept to define a multicriteria decision analysis. Ecological Economics 93: 128-136. - doi: 10.1016/j.ecolecon.2013.05.007 Fratini R (2005). Risorse forestali della Toscana e aspetti riguardanti il mercato del legno locale [Forest resources of Tuscany and aspects concerning the local wood market]. Agriregionieuropa 11 (42). Web site. [in Italian] [online] URL: http://agriregionieuropa.univpm.it/it/content/ar ticle/31/42/risorse-forestali-della-toscana-e-aspe tti-riguardanti-il-mercato-del-legno

Grêt-Regamey A, Weibel B, Kienast F, Rabe SE, Zulian G (2015). A tiered approach for mapping ecosystem services. Ecosystem Services 13: 1627. - doi: 10.1016/j.ecoser.2014.10.008

Hernández-Morcillo $M$, Plieninger T, Bieling $C$ (2013). An empirical review of cultural ecosystem service indicators. Ecological indicators 29: 434-444. - doi: 10.1016/j.ecolind.2013.01.013

Hollenstein L, Purves R (2010). Exploring place through user-generated content: using Flickr tags to describe city cores. Journal of Spatial Information Science 1: 21-48. [online] URL: http://josis.org/index.php/josis/article/viewArtic le/13
Kirilenko AP, Molodtsova T, Stepchenkova SO (2015). People as sensors: mass media and local temperature influence climate change discussion on Twitter. Global Environmental Change 30: 92-100. - doi: 10.1016/j.gloenvcha.2014.11.003 Komossa F, Van Der Zanden EH, Schulp CJ, Verburg PH (2018). Mapping landscape potential for outdoor recreation using different archetypical recreation user groups in the European Union. Ecological Indicators 85: 105-116. - doi: 10.1016/j.ecolind.2017.10.015

Langemeyer J, Calcagni F, Barò F (2018). Mapping the intangible: using geolocated social media data to examine landscape aesthetics. Land Use Policy 77: 542-552. - doi: 10.1016/j.landuse pol.2018.05.049

Levin N, Lechner AM, Brown G (2017). An evaluation of crowd-sourced information for assessing the visitation and perceived importance of protected areas. Applied Geography 79: 115-126. - doi: 10.1016/j.apgeog.2016.12.009

Li L, Goodchild MF, Xu B (2013). Spatial, temporal, and socioeconomic patterns in the use of Twitter and Flickr. Cartography and Geographic Information Science 40 (2): 61-77. - doi: 10.1080/ 15230406.2013.777139

Lupp G, Konold W, Bastian O (2013). Landscape management and landscape changes towards more naturalness and wilderness: Effects on scenic qualities - The case of the Müritz $\mathrm{Na}$ tional Park in Germany. Journal for Nature Conservation 21: 10-21. - doi: 10.1016/j.jnc.2012.08. 003

Merow C, Smith MJ, Silander JA (2013). A practical guide to MaxEnt for modeling species' distributions: what it does, and why inputs and settings matter. Ecography 36 (10): 1058-1069. doi: 10.1111/j.1600-0587.2013.07872.x

Milcu Al, Hanspach J, Abson D, Fischer J (2013). Cultural ecosystem services: a literature review and prospects for future research. Ecology and Society 18 (3): 44. - doi: 10.5751/ES-05790-1803 44

MEA (2005). Ecosystems and human well-being: synthesis. Island Press, Washington, DC, USA, pp. 155.

Nahuelhual L, Carmona A, Lozada P, Jaramillo A, Aguayo M (2013). Mapping recreation and ecotourism as a cultural ecosystem service: An application at the local level in Southern Chile. Applied Geography 40: 71-82. - doi: 10.1016/j.apgeo g.2012.12.004

Nesbitt L, Hotte N, Barron S, Cowan J, Sheppard SRJ (2017). The social and economic value of cultural ecosystem services provided by urban forests in North America: a review and suggestions for future research. Urban Forestry and Urban Greening 25: 103-111. - doi: 10.1016/j.ufug. 2017.05.005

Nov O, Naaman M, Ye C (2010). Analysis of participation in an online photo-sharing community: a multidimensional perspective. Journal of the Association for Information Science and Technology 61 (3): 555-566. - doi: 10.1002/asi.21 278

Oteros-Rozas E, Martín-López B, Fagerholm N, Bieling C, Plieninger T (2018). Using social media photos to explore the relation between cultural ecosystem services and landscape features across five European sites. Ecological Indicators 94 (2): 74-86. - doi: 10.1016/j.ecolind. 
2017.02.009

Paracchini ML, Zulian G, Kopperoinen L, Maes J, Schägner JP, Termansen M, Bidoglio G (2014). Mapping cultural ecosystem services: a framework to assess the potential for outdoor recreation across the EU. Ecological Indicators 45: 371-385. - doi: 10.1016/j.ecolind.2014.04.018

Pastorella F, Giacovelli G, De Meo I, Paletto A (2017). People's preferences for Alpine forest landscapes: results of an internet-based survey. Journal of Forest Research 22 (1): 36-43. - doi: 10.1080/13416979.2017.1279708

Phillips SJ, Anderson RP, Schapire RE (2006). Maximum entropy modeling of species geographic distributions. Ecological Modelling 190 (3-4): 231-259. - doi: 10.1016/j.ecolmodel.2005.0 3.026

Phillips SJ, Dudík M (2008). Modeling of species distributions with Maxent: new extensions and a comprehensive evaluation. Ecography 31 (2): 161-175. - doi: 10.1111/j.0906-7590.2008.5203.x

Poor EE, Loucks C, Jakes A, Urban DL (2012). Comparing habitat suitability and connectivity modeling methods for conserving pronghorn migrations. PLoS ONE 7 (11): e49390. - doi: 10.13 71/journal.pone.0049390

Rabe SE, Gantenbein R, Richter KF, Grêt-Regamey $A$ (2018). Increasing the credibility of expert-based models with preference surveys Mapping recreation in the riverine zone. Ecosystem Services 31: 308-317. - doi: 10.1016/j.eco ser.2017.12.011

Ribe RG (2009). In-stand scenic beauty of variable retention harvests and mature forests in the U.S. Pacific Northwest: the effects of basal area, density, retention pattern and down wood. Journal of Environmental Management 91: 245-260. - doi: 10.1016/j.jenvman.2009.08.0 14

Richards DR, Friess DA (2015). A rapid indicator of cultural ecosystem service usage at a fine spatial scale: content analysis of social media photographs. Ecological Indicators 53: 187-195. - doi: 10.1016/j.ecolind.2015.01.034
Richards DR, Tunçer B (2017). Using image recognition to automate assessment of cultural ecosystem services from social media photographs. Ecosystem Services 31: 318-325. - doi: 10.1016/j.ecoser.2017.09.004

Rovai M, Andreoli M, Gorelli G, Jussila H (2016). A DSS model for the governance of sustainable rural landscape: a first application to the cultural landscape of Orcia Valley (Tuscany, Italy). Land Use Policy 56: 217-237. - doi: 10.1016/j.land usepol.2016.04.038

Saarikoski H, Mustajoki J, Barton DN, Geneletti D, Langemeyer J, Gomez-Baggethun E, Marttunen M, Antunes P, Keune H (2016). Multi-criteria decision analysis and cost-benefit analysis: comparing alternative frameworks for integrated valuation of ecosystem services. Ecosystem Services 22: 238-249. - doi: 10.1016/j.ecoser. 2016.10.014

Sacchelli S (2018). A decision support system for trade-off analysis and dynamic evaluation of forest ecosystem services. iForest - Biogeosciences and Forestry 11: 171-180. - doi: 10.3832/ ifor2416-010

Schirpke U, Hölzler S, Leitinger G, Bacher M, Tappeiner U, Tasser E (2013). Can we model the scenic beauty of an alpine landscape? Sustainability 5: 1080-1094. - doi: 10.3390/su5031080

Schirpke U, Timmermann F, Tappeiner U, Tasser $E$ (2016). Cultural ecosystem services of mountain regions: modelling the aesthetic value. Ecological Indicators 69: 78-90. - doi: 10.1016/j. ecolind.2016.04.001

Schirpke U, Meisch C, Marsoner T, Tappeiner U (2018). Revealing spatial and temporal patterns of outdoor recreation in the European Alps and their surroundings. Ecosystem Services 31: 336350. - doi: 10.1016/j.ecoser.2017.11.017

Scott MJ, Canter DV (1997). Picture or place? A multiple sorting study of landscape. Journal of Environmental Psychology 17 (4): 263-281. - doi: 10.1006/jevp.1997.0068

Sun Y, Fan H, Helbich M, Zipf A (2013). Analyzing human activities through volunteered geo- graphic information: using Flickr to analyze spatial and temporal pattern of tourist accommodation. In: "Progress in Location-Based Services” (Krisp J ed). Lecture Notes in Geoinformation and Cartography, Springer, Berlin, Heidelberg, Germany, pp. 55-69. - doi: 10.1007/9783-642-34203-5 4

Swets JA (1988). Measuring the accuracy of diagnostic systems. Science 240: 1285-1293. - doi: 10.1126/science.3287615

Tahvanainen L, Tyrväinen L, Ihalainen M, Vuorela $\mathrm{N}$, Kolehmainen $\mathrm{O}$ (2001). Forest management and public perceptions - visual versus verbal information. Landscape and Urban Planning 53: 53-70. - doi: 10.1016/S0169-2046(00)00137-7 Tenerelli P, Demsar D, Luque S (2016). Crowdsourcing indicators for cultural ecosystem services: a geographically weighted approach for mountain landscapes. Ecological Indicators 64: 237-248. - doi: 10.1016/j.ecolind.2015.12.042 Walden-Schreiner C, Leung YF, Tateosian L (2018). Digital footprints: incorporating crowdsourced geographic information for protected area management. Applied Geography 90: 4454. - doi: 10.1016/j.apgeog.2017.11.004

Westcott F, Andrew ME (2015). Spatial and environmental patterns of off-road vehicle recreation in a semi-arid woodland. Applied Geography 62: 97-106. - doi: 10.1016/j.apgeog.2015.04. 011

Yoshimura N, Hiura T (2017). Demand and supply of cultural ecosystem services: use of geo-tagged photos to map the aesthetic value of landscapes in Hokkaido. Ecosystem Services 24: 6878. - doi: 10.1016/j.ecoser.2017.02.009

\section{Supplementary Material}

Appendix 1 - Script applied for the extraction of tag-cloud.

Link: Bernetti_2821@supplo01.pdf 